\title{
Frecuencias alélicas y genotípicas del gen Kappa Caseína y ßeta Lactoglobulina en ganado Pardo Suizo
}

\author{
Allelic and genotypic frequencies of the Kappa Casein and ßeta Lactoglobulin gene in Brown Swiss cattle
}

\author{
Sonaira Gabriela Andrade Ortega ${ }^{1}$, Julio Omar López Flores², Isaías Ezequiel Sánchez Gómez ${ }^{3}$ \\ ${ }^{1}$ MV. Graduado Universidad Nacional Agraria, ORCID: https://orcid.org/0000-0002-7396-9846/ sonairaortega@gmail.com \\ ${ }^{2}$ MV. MSc. en Biotecnología, Facultad de Ciencia Animal, ORCID: https://orcid.org/0000-0002-7325-4912/ julio.lopez@ci.una.edu.ni \\ ${ }^{3}$ MSc. en Sanidad vegetal, Facultad de Agronomía, ORCID: https://orcid.org/0000-0002-6604-1660 / isanchez@ci.una.edu.ni \\ Universidad Nacional Agraria
}

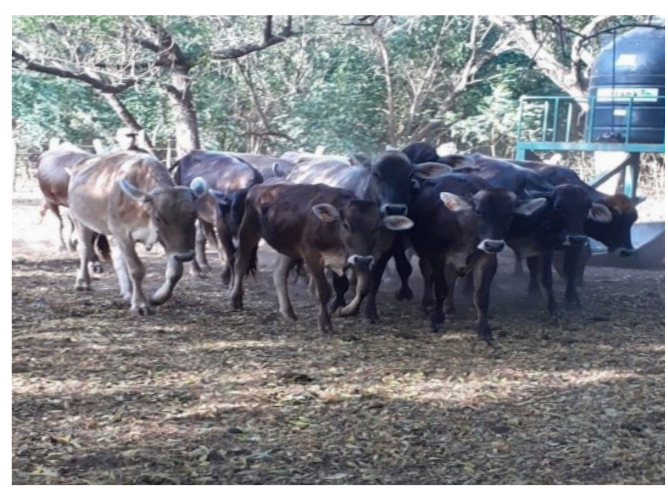

\section{RESUMEN}

La raza Pardo Suizo es una de las razas con gran desarrollo genético orientada a la producción de mayores volúmenes de leche. El objetivo de este estudio fue determinar las frecuencia alélicas y genotípicas del gen de Kappa caseína y ßeta Lactoglobulina en ganado con encaste Pardo Suizo y Brahaman. Se seleccionaron 20 hembras bovinas, ubicadas en la finca Santa Rosa de la Facultad de Ciencia Animal de la Universidad Nacional Agraria (UNA). Se extrajo el ADN a partir de sangre total con EDTA. Con la técnica PCR se amplifico fragmentos del gen de Kappa caseína de $351 \mathrm{pb}$ y fragmentos de $262 \mathrm{pb}$ para el gen Beta lactoglobulina. La genotipificación se realizó con la técnica PCR-FRLP y la separación de fragmentos para ambos genes se realizó en un gel de agarosa al $2 \%$. Las frecuencias genotípicas encontradas para Kappa caseína fueron de $0.25(5 / 20), 0.65(13 / 20), 0.10(2 / 20)$, para los genotipos $\mathrm{AA}, \mathrm{AB}$ y $\mathrm{BB}$ respectivamente, resultando más frecuente el heterocigoto AB. Las frecuencias alélicas para este mismo gen fueron de 0.575 y 0.425 para el alelo A y B. Las frecuencias genotípicas para ßeta Lactoglobulina fueron 0.05 (1/20), $0.1(2 / 20)$, $0.85(17 / 20)$ para los genotipos AA, AB y BB respectivamente, resultando más frecuente los individuos homocigóticos $\mathrm{BB}$. Las frecuencias alélicas resultaron ser de 0.1 y 0.9 para los alelos A y $\mathrm{B}$ de $\beta$ eta Lactoglobulina. Los individuos evaluados para Kappa caseína presentaron baja proporción del genotipo deseable BB, mientras que para ßeta Lactoglobulina la proporción de individuos con genotipo deseable BB fue mayor.

Palabras clave: genotipificación, gen, amplicón.

Abreviatura: PCR-RFLP: Reacción en cadena de la polimerasa fragmentos de restricción de longitud polimórfica.

\section{ABSTRACT}

The Brown Swiss breed is one of the breeds with great genetic development oriented to the production of greater volumes of milk. The objective of this study was to determine the allelic and genotypic frequencies of the Kappa casein and Beta Lactoglobulin gene in cattle with Brown Swiss and Brahaman crosses. 20 female bovine animals were selected, located in the Santa Rosa farm of the Faculty of Animal Science of the National Agrarian University (UNA). DNA was extracted from whole blood with EDTA. DNA was extracted from whole blood with EDTA. With the PCR technique, fragments of the Kappa casein gene of $351 \mathrm{bp}$ and fragments of $262 \mathrm{bp}$ for the Beta lactoglobulin gene were amplified. Genotyping was carried out with the PCR-FRLP technique and the separation of fragments for both genes was carried out on a $2 \%$ agarose gel. The genotype frequencies found for Kappa casein were 0.25 $(5 / 20), 0.65(13 / 20), 0.10(2 / 20)$, for the AA, AB and BB genotypes respectively, with the heterozygous $\mathrm{AB}$ being more frequent. The allele frequencies for this same gene were 0.575 and 0.425 for alleles $\mathrm{A}$ and $\mathrm{B}$. The genotype frequencies for $\beta$ eta Lactoglobulin were $0.05(1 / 20), 0.1(2 / 20), 0.85(17 / 20)$ for the AA genotypes, AB and $\mathrm{BB}$ respectively, with homozygous $\mathrm{BB}$ being more frequent. The allele frequencies were found to be 0.1 and 0.9 for the $\mathrm{A}$ and $\mathrm{B}$ alleles of $\beta$ eta Lactoglobulin. The individuals evaluated for Kappa casein presented a low proportion of the desirable BB genotype, while for $\beta$ eta Lactoglobulin the proportion of individuals with the desirable BB genotype was higher.

Key words: genotyping, gene, amplicon

Abbreviation: PCR-RFLP. Polymerase chain reaction - polymorphic length restriction fragments.
Recibido: 2 de julio del 2020 Aceptado: 25 de febrero del 2021

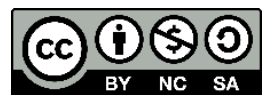

Los artículos de la revista La Calera de la Universidad Nacional Agraria, Nicaragua, se comparten bajo términos de la licencia Creative Commons: Reconocimiento, No Comercial, Compartir Igual. Las autorizaciones adicionales a las aquí delimitadas se pueden obtener en el correo edgardo.jimenez@ci.una.edu.ni

C) Copyright 2021. Universidad Nacional Agraria (UNA) 


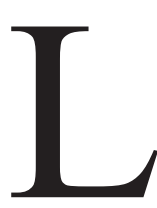

a ganadería en Nicaragua inicia en el año 1526, con la colonización española, los primeros ejemplares fueron introducidos por Pedrarias Dávila poniendo las bases de lo que hoy es una industria en Nicaragua y de importancia en la economía del país (Espinoza y Urbina, 2016). Según Lopez (2019), director ejecutivo de la cámara nicaragüense del sector lácteo (CANISLAC), "Nicaragua ha venido desarrollando capacidades para ser un país con alta producción de leche, además las condiciones climatológicas y circunstancias del país han beneficiado, para que el sector lácteo tenga un excelente desarrollo". En las últimas décadas, el sector ganadero se ha transformado a un ritmo sin precedentes, con la creciente demanda de alimentos derivados de los animales, con la ayuda de importantes innovaciones tecnológicas y cambios estructurales en el sector ganadero; esta creciente demanda se ha satisfecho principalmente por la producción ganadera comercial y las cadenas alimentarias asociadas, como lo indica la Organización de las Naciones Unidas para la Alimentación y la Agricultura (FAO, 2014).

Para el 2018, el sector lácteo sufrió una drástica caída en las exportaciones, sin embargo, CANISLAC mantiene una cifra alta cada año; gracias al excelente dinamismo de las exportaciones y el trabajo brindado por CANISLAC, Nicaragua es el primer país con exportaciones a Centroamérica, y a nivel latinoamericano se ubica en el cuarto lugar, después de Uruguay, Argentina y Brasil (López, 2019). La ganadería nacional prácticamente se encuentra en manos de pequeños y medianos productores con explotaciones bovinas de doble propósito, lo que se logra de los cruces de razas de carne y leche, además de ganado criollo (Espinoza y Urbina, 2016).

Según Giménez (2016), la raza bovina Pardo Suizo, es una de las más antiguas, sus orígenes datan de 2000 años antes de Cristo. Con datos relevantes, se puede confirmar que su nacimiento con características definidas como raza, se remonta a mediados del siglo XIII en los valles de los Alpes Suizos; en el siglo XIX se establecieron registros de producción sobre carne y leche, además es una de las razas con gran desarrollo genético orientado a la producción de mayores volúmenes de leche.

La leche derivada de animales con genotipo AA tiene menor porcentaje de Kappa caseína $(\kappa-\mathrm{CN})$ y como consecuencia de esto, una mayor proporción de micelas grandes. Por el contrario, la leche derivada de animales con genotipo $\mathrm{BB}$ presenta mayor proporción de $\kappa-\mathrm{CN}$ y micelas más pequeñas. Esta característica explica la formación de un cuajo más firme y una mayor retención de sólidos, lo que resulta en un rendimiento superior durante la producción de queso, comparada con la leche producida por animales con genotipo $\mathrm{\kappa}$-CN AA (Requena, 2007). El objetivo de esta investigación es determinar las frecuencias alélicas y genotípicas del gen de Kappa caseína y ßeta Lactoglobulina en ganado con encaste $75 \%$ Pardo Suizo y $25 \%$ Brahaman en la finca Santa Rosa, propiedad de la Facultad de Ciencia Animal de la Universidad Nacional Agraria (UNA) en Nicaragua, para proponer alternativas de mejoramiento genético en el hato ganadero.

\section{MATERIALES Y MÉTODOS}

Ubicación del área de estudio. La determinación de frecuencias alélicas y genotípicas del gen de Kappa caseína y ßeta-Lactoglobulina se realizó en el laboratorio de Microbiología de la Universidad Nacional Agraria, Facultad de Agronomía (UNA), ubicada en el km 12 1/2 Carretera Norte Managua, Nicaragua, con coordenadas $86^{\circ} 09^{\prime} 36^{\prime \prime}$ de longitud Oeste y $12^{\circ} 08^{\prime} 15^{\prime \prime}$ de latitud Norte, como lo indica el Instituto Nicaragüense de Estudios Territoriales (INETER, 2018).

Tipo de estudio. Esto estudio se realizó de manera descriptiva y consistió en determinar las frecuencias alélicas y genotípicas del gen Kappa caseína y ßeta Lactoglobulina del ganado bovino antes señalado.

Toma de muestra sanguínea. La población bovina estudiada fue de 20 hembras con encaste de $75 \%$ Pardo Suizo y $25 \%$ Brahmán. La toma de muestra sanguínea fue venosa, mediante la localización de la vena coccígea, se levantó la cola del animal con suavidad hasta colocarla en posición vertical, sujetándola en el tercio medio posterior, desinfectando el área con alcohol al $70 \%$ y extrayendo 2 $\mathrm{ml}$ de sangre total con una jeringa de $5 \mathrm{ml}$; luego se depositó la sangre en un tubo de ensayo que contiene anti coagulante EDTA en concentración de $10.8 \mathrm{mg}$, posteriormente se invirtió varias veces el tubo para que la sangre y el anticoagulante se mezclarán (Zambrano y Díaz, 2012). Las muestras fueron trasladadas en un recipiente térmico al laboratorio de microbiología de la Facultad de Agronomía.

Parámetros de selección. La selección de hembras bovinas en esta investigación fue por conveniencia, tomando como criterio de inclusión hembras en edades de 12 a 18 meses, clínicamente sanas (sin alteraciones en frecuencia respiratoria, frecuencia cardíaca y temperatura), reproductivamente sanas, libres de tuberculosis y brucelosis.

Extracción del ADN. La extracción de ADN se realizó por el método CTAB (Bromuro de hexadeciltrimetilamonio) descrito por Doyle y Doyle (1990), que consiste en:

Calentar el buffer de extracción CTAB por 30 minutos a $65^{\circ} \mathrm{C}$. En vez de tejido vegetal se colocó $50 \mu 1$ de sangre total con EDTA en concentración de $10.8 \mathrm{mg}$ en un tubo Eppendorf y se adicionó $500 \mu \mathrm{l}$ de CTAB $\quad 2 \%$ (buffer) y se incubó a $65{ }^{\circ} \mathrm{C}$ por 30 minutos. Posterior a la incubación, 
se adicionaron $400 \mu \mathrm{l}$ de cloroformo-alcohol isoamílico (24:1), se centrifugó por 10 minutos a 14 $000 \mathrm{rpm}$. Se tomó el sobrenadante y se transfirió a un nuevo tubo Eppendorf de $1.5 \mathrm{ml}$, se adicionó 200 $\mu \mathrm{l}$ de isopropanol, se incubó por 15 minutos a -20 ${ }^{\circ} \mathrm{C}$, se centrifugó a $14000 \mathrm{rpm}$ por cinco minutos y se eliminó el sobrenadante. Al pellet resultante se le adicionó $100 \mu \mathrm{l}$ de etanol y se mezcló por inversión, se centrifugó a $14000 \mathrm{rpm}$ por tres minutos, se eliminó el sobrenadante y se dejó secar a temperatura ambiente. Posteriormente, el pellet fue hidratado en $100 \mu \mathrm{l}$ de agua calidad molecular, se adicionó $1 \mu \mathrm{l}$ de la ribonucleasa (ARNasa) y se incubó por 20 minutos a $37^{\circ} \mathrm{C}$. El ADN extraído se mantuvo a una temperatura de $-20^{\circ} \mathrm{C}$ hasta su uso.

Amplificación del gen de Kappa caseína y ßeta Lactoglobulina. La amplificación del gen de la Kappa caseína se realizó mediante la técnica de PCR convencional con reacciones de $25 \mu \mathrm{l}$ de volumen final, que consistió en mezclar $2 \mu \mathrm{l}$ de la muestra a estudiar $12.5 \mu \mathrm{l}$ de Master Mix (PROMEGA), $7.5 \mu \mathrm{l}$ de agua libre de nucleasas y 2 $\mu l$ del par de cebadores utilizados por Rojas et al. (2009), BLKC delantero 5'- ATT AGCCCATTTCGCCTTCT-3' y BLKC-reverso 5'-ATT TATGGCCATTCCACCAA-3', respectivamente que producen un amplicón de 351 pares de bases(pb). La PCR se desarrolló en un termociclador Eppendorf bajo las siguientes condiciones: Desnaturalización inicial $95{ }^{\circ} \mathrm{C}$ durante tres minutos, 35 ciclos a $94{ }^{\circ} \mathrm{C}$ durante 45 segundos $52.4^{\circ} \mathrm{C}$ por 45 segundos seguido de $72{ }^{\circ} \mathrm{C}$ por 60 segundos y una extensión final a $72{ }^{\circ} \mathrm{C}$ durante siete minutos. Para visualizar los fragmentos se depositó $8 \mu 1$ del producto PCR con $1.5 \mu \mathrm{l}$ del colorante de carga 6x loading Dye en un gel de agarosa al $2 \%$ teñido con Gel red. El gel se colocó en una cámara de electroforesis con buffer TBE $1 \mathrm{X}$. La electroforesis se llevó a cabo por un periodo de una hora a 80 voltios a 85 miliamperios luego se procedió a visualizar las bandas en el transluminador registrándose los resultados fotográficamente.

La amplificación del gen de Beta Lactoglobulina se realizó mediante la técnica de PCR convencional con reacciones de $25 \mu 1$ de volumen final, la que consistió en mezclar $2 \mu \mathrm{l}$ de la muestra a estudiar, $12.5 \mu \mathrm{l}$ de Master Mix (PROMEGA), $7.5 \mu 1$ de agua libre de nucleasas y $2 \mu 1$ del par de cebadores utilizados por Rojas et al. (2010), BLGP3-F 5' GTCCTTGTGCTGGACACCGACTACA-3'y BLGP4reversa 5'-CAGGACACCGG-CTCCCGGTATATGA-3', respectivamente que producen un amplicon de $262 \mathrm{pb}$. La PCR se desarrolló en un termociclador Eppendorf bajo las siguientes condiciones: Desnaturalización inicial $95{ }^{\circ} \mathrm{C}$ durante tres minutos, 35 ciclos a $94{ }^{\circ} \mathrm{C}$ durante 45 segundos, $64.2^{\circ} \mathrm{C}$ por 45 segundos seguido de $72{ }^{\circ} \mathrm{C}$ por 60 segundos y una extensión final a $72{ }^{\circ} \mathrm{C}$ por siete minutos. Para visualizar los fragmentos se depositó $8 \mu \mathrm{l}$ del producto PCR con $1.5 \mu \mathrm{l}$ del colorante de carga 6x loading Dye en un gel de agarosa al $2 \%$ teñido con Gel red. El gel se colocó en una cámara de electroforesis con buffer TBE 1X. La electroforesis se llevó a cabo por un periodo de una hora y treinta minutos a 80 voltios a 85 miliamperios, luego se procedió a visualizar las bandas en el transluminador registrándose los resultados fotográficamente.

Genotipificación del gen de Kappa caseína. La genotipificación se realizó mediante la técnica PCR-FRLP que consiste en:

Usar el producto de la amplificación de la PCR con los iniciadores BLKC delantero y BLKC-reverso. El producto de la PCR convencional se sometió a digestión con la enzima Hinf I en un volumen final de $10 \mu \mathrm{l}$. El procedimiento consistió en adicionar $8 \mu \mathrm{l}$ del producto amplificado PCR, $2 \mu \mathrm{l}$ de la enzima de restricción. Posteriormente se incubó a $37^{\circ} \mathrm{C}$ por una hora en un termociclador Eppendorf. Después de la incubación se procedió a realizar la separación de los fragmentos en un gel de agarosa al $2 \%$ en solución de Tris -Borato-EDTA buffer 1X. Los genotipos homocigotos AA mostraron dos fragmentos de 134/132 pb y $84 \mathrm{pb}$, los genotipos homocigotos $\mathrm{BB}$ dos fragmentos de $266 \mathrm{pb}$ y 84 $\mathrm{pb}$, mientras que los genotipos heterocigotos $\mathrm{AB}$ presentaron tres fragmentos de 266pb, 134/132pb y 84 pb (Rojas et al., 2009, p. 646).

Genotipificación del gen de la ßeta Lactoglobulina. La genotipificación de ßeta Lactoglobulina se realizó mediante la técnica PCR-FRLP que consiste en:

Usar el producto de la amplificación de la PCR con los iniciadores BLGP3 delantero y BLGP4 reverso. El producto PCR se sometió a digestión con enzima Hae III en un volumen final de $10 \mu \mathrm{l}$. El procedimiento consistió en adicionar $8 \mu \mathrm{ldel}$ producto amplificado PCR, $2 \mu \mathrm{l}$ de la enzima de restricción. Posteriormente se incubó a $37^{\circ} \mathrm{C}$ por una hora en un termociclador Eppendorf. Después de la incubación se procedió a realizar separación de los fragmentos en un gel de agarosa al $2 \%$ en solución de Tris -Borato-EDTA buffer 1X. Los genotipos homocigotos AA mostraron dos fragmentos de $153 / 109 \mathrm{pb}$ y $109 \mathrm{pb}$, los genotipos heterocigotos $\mathrm{AB}$ presentaron tres fragmentos de 153,109 y $74 / 79$ $\mathrm{pb}$ mientras que los genotipos homocigotos $\mathrm{BB}$ mostraron dos fragmentos de 109 y 74/79 pb (Rojas et al., 2009, p. 177).

Cálculo de frecuencias genotípicas y alélicas. Consistió en calcular la proporción de cada alelo en un locus determinado 
en una población específica, el resultado de la suma de las frecuencias alélicas en una población siempre se expresa con un valor igual a uno o como $100 \%$ (Griffiths, 2002; Falconer y Mackey, 2001). Se calculó la frecuencia genotípica y alélica mediante las fórmula descrita por Hernández y Trejos, (2014).

$$
\mathrm{F}(\text { Genotípica })=\frac{\mathrm{N} .^{\circ} \text { de genotipos }}{\mathrm{N} .^{\circ} \text { de muestras }}
$$

Frecuencia alélica

$$
\mathrm{p}(\mathrm{A})=\frac{1(\mathrm{AA})+0.5(\mathrm{AB})}{\mathrm{N}} \quad \mathrm{q}(\mathrm{B})=\frac{1(\mathrm{BB})+0.5(\mathrm{AB})}{\mathrm{N}}
$$

Donde:

$\mathrm{N}^{\mathrm{o}}$ : Número de muestras

p(A): Frecuencia del alelo A

q (B): Frecuencia del alelo B

AB: Heterocigotos de los alelos A y B

0.5: Constante de la mitad de cada alelo

Variables evaluadas. Las variables fueron la determinación de frecuencias alélicas y genotípicas de los alelos Kappa caseína y Beta-globulina a partir de los resultados de la PCR y PCR-FRLPs.

Frecuencias alélicas. La frecuencia génica o alélica se estiman contando el número de veces que es observado el alelo de un locus, dividiéndolo entre el número de alelos estudiados (Hernández y Trejo, 2014).

Frecuencias genotípicas. Para obtener el porcentaje de las frecuencias genotípica se divide cada número de combinaciones observadas (genotipo) entre el número total de la muestra analizada y posteriormente multiplicándolo por 100 (Hernández y Trejos, 2014).

Análisis de datos. Los datos obtenidos fueron analizados a través de una hoja de Excel para el cálculo de las frecuencias alélicas y genotípicas de las hembras muestreadas, utilizando las fórmulas de Hernández y Trejos (2014).

\section{RESULTADOS Y DISCUSIÓN}

Amplificación del gen de la Kappa caseína. Con la técnica PCR se amplificaron fragmentos de $351 \mathrm{pb}$ correspondiente al gen de la Kappa caseína con el par de cebadores BLKC delantero y BLKC-reverso en 20 muestras de hembras bovinas con encaste Pardo Suizo Brahmán (Figura 1). La amplificación de los fragmentos fue óptima para ser digeridos con la enzima de restricción Hinf I (Figura 1).

Producto de la digestión con la enzima de restricción Hinf I se determinó el genotipo AA en cinco muestras, observándose patrones de banda de 134/132 pb y $84 \mathrm{pb}$, en una muestra se observaron fragmentos de $266 \mathrm{pb}$ y $84 \mathrm{pb}$ correspondiendo al genotipo $\mathrm{BB}$, mientras que en 11 muestras se observó el genotipo AB con fragmentos de 266 pb 134/132 pb y 84 pb (Figura 2).

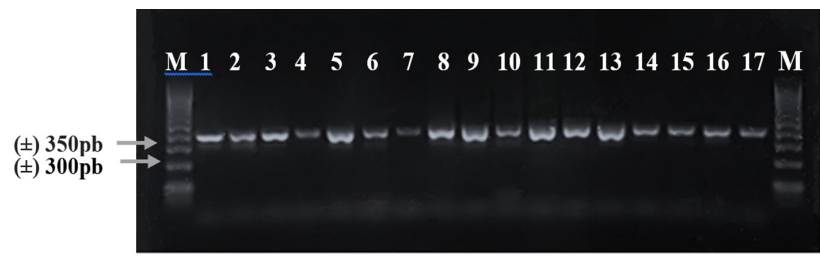

Figura 1. Electroforesis en gel de agarosa de los productos PCR del gen de K-caseína amplificado con los cebadores BLKC-delantero y BLKC-reverso en muestras de hembras bovinas, identificadas por los números $(1,2,3,4,5,6,7,8,9,10,11,12,13,14,15,16,17)$, la letra $\mathrm{M}$ indica el marcador de peso molecular de $100 \mathrm{pb}$.

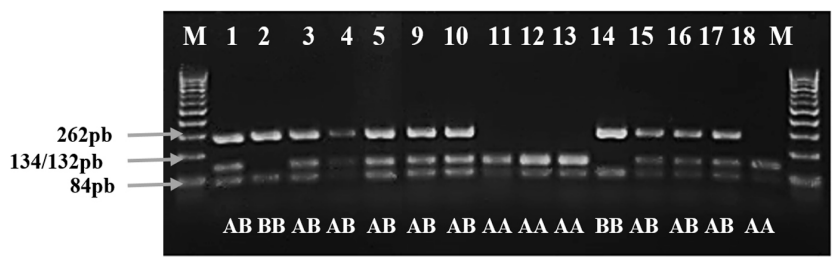

Figura 2. Electroforesis en gel de agarosa de los productos PCR del gen de K-caseína, digeridos con la enzima de restricción Hilf I. La letra $\mathrm{M}$ indica el marcador molecular de $100 \mathrm{pb}$, las muestras número $1,3,4,5,9,10,15,16,17$ corresponden a hembras bovinas con genotipo $\mathrm{AB}$, mientras que el número 2 y 14 corresponden al genotipo $\mathrm{BB}$. Los números 11, 12, 13, 18 corresponden al genotipo AA.

Amplificación del gen ßeta Lactoglobulina. Con la técnica PCR se amplificaron fragmentos de $262 \mathrm{pb}$ correspondientes al gen de la ßeta Lactoglobulina con el par de cebadores específicos BLGP delantero y BLGP4-reversa en 20 muestras procedentes de hembras bovinos (Figura 3). La amplificación fue óptima para ser digeridos con la enzima de restricción Hae III (Figura 4).

El resultado de la digestión con la enzima de restricción Hae III mostró patrones de bandas de 153 pb y $109 \mathrm{pb}$ para el genotipo AA en una muestra, mientras que en 17 muestras se observaron fragmentos de $109 \mathrm{pb}$ y 74/ $79 \mathrm{pb}$ que corresponden al genotipo BB, y en dos muestras se observaron fragmentos de $153 \mathrm{pb}, 109 \mathrm{pb}$ y 74/79 pb correspondiente al genotipo AB (Figura 4).

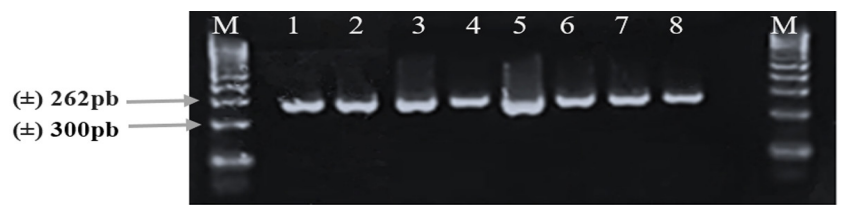

Figura 3. Electroforesis en gel de agarosa de los productos PCR del gen de $\beta$ eta Lactoglobulina amplificados con los cebadores BLGP3delantero y BLGP4- reverso en muestras de hembras bovinas, identificadas por los números $(1,2,3,4,5,6,7,8)$, la letra $\mathrm{M}$ indica el marcador de peso molecular de $100 \mathrm{pb}$. 

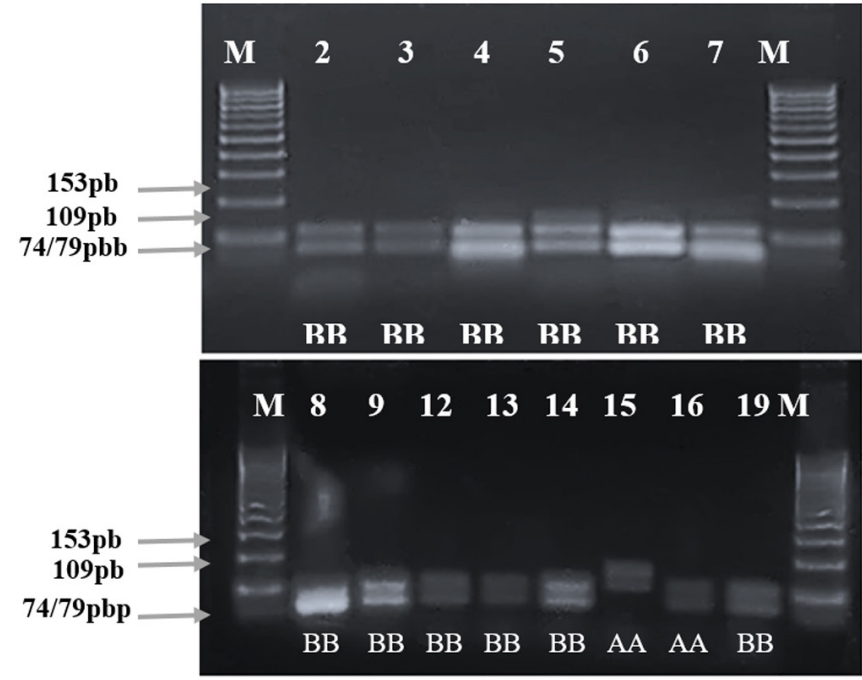

Figura 4. Electroforesis en gel de agarosa de los productos PCR del gen de K-caseína, digeridos con la enzima de restricción Hae III. Con la letra M se indica el marcador molecular de $100 \mathrm{pb}$, las muestras número $(15,16)$ corresponde a individuos con genotipo $\mathrm{AA}$, mientras que los números $(2,3,4,5,6,7,8,9,12,13,14,19)$ al genotipo BB.

Ruiz, (2011); Requena (2007); Uffo et al., (2006) y Benavides, (2003), plantean que el genotipo homocigoto BB del gen de Kappa caseína estudiada en bovinos, contiene isoleucina (ATC) y Alanina (GCT), mostrando alto contenido proteico, mayor estabilidad al calor, coagulación, un cuajo más consistente y rendimiento quesero del $5 \%$ al $10 \%$ en comparación con el genotipo AA.

Rojas et al. (2010) indican que el alelo B de beta lactoglobulina ( $\beta-L G)$ es el más ancestral, debido a su alta frecuencia y prevalencia en razas europeas, Cebuinas y mestizos como Pardo Suizo, Jersey, Guernsey, Gyr, Cebú asiático y africano, así como en razas italianas.

Requena et al. (2007) resumen que la variante A esta asociada con mayor nivel de $\beta$-LG y proteínas totales del suero de la leche, y con menor contenido de caseínas y grasa. Por otra parte, los animales con genotipo $\beta$-LG BB tienen un menor contenido de $\beta$-LG y un mayor contenido de caseínas, proteínas totales y grasa en la leche, lo que resulta en mejores propiedades para la producción de queso. Además, este genotipo ha sido correlacionado con un mayor rendimiento en litros de leche con respecto al genotipo AA, habiéndose observado para el genotipo $\mathrm{AB}$ un rendimiento intermedio.

Frecuencias genotípicas y alélicas de los genes Kappa caseína y ßeta Lactoglobulina. En este estudio las frecuencias genotípicas obtenidas para el gen de Kappa caseína fueron $0.3(6 / 20), 0.60(12 / 20)$ y $0.10(2 / 20)$ para los genotipos $\mathrm{AA}, \mathrm{AB}$ y $\mathrm{BB}$, respectivamente. El genotipo más frecuente fue el $\mathrm{AB}$, seguido del $\mathrm{AA}$ y el menos frecuente el $\mathrm{BB}$, mientras que las frecuencias alélicas fueron $0.60 \mathrm{y}$ 0.40 para los alelos A y B, respectivamente, habiendo sido el alelo más frecuente el A. En relación con el gen de ßeta Lactoglobulina la frecuencia genotípica fue $0.10,0.80$ y 0.10 para el genotipo $\mathrm{AA}, \mathrm{BB}$ y $\mathrm{AB}$ respectivamente. El genotipo más frecuente el $\mathrm{BB}$, seguido del $\mathrm{AB}$ y el $\mathrm{AA}$, mientras que las frecuencias alélicas fueron 0.15 y 0.85 para los alelos A y $\mathrm{B}$ respetivamente, resultado el alelo más frecuente el B. EL predomino de los alelos A y B está determinada por las diferentes razas y los cruces que se realizan para mejorar el hato ganadero.

Cuadro 1. Frecuencias alélica y genotípica del gen de Kappa caseína y ßeta Lactoglobulina en hembras bovinas de la raza con encaste Pardo Suizo de la UNA

\begin{tabular}{ccccccc}
\hline Raza & Protéína & \multicolumn{2}{c}{ Frecuencia alélica } & \multicolumn{3}{c}{ Frecuencia genotipica } \\
\hline \multirow{3}{*}{ Pardo Suizo } & & $\mathrm{A}$ & $\mathrm{B}$ & $\mathrm{AA}$ & $\mathrm{BB}$ & $\mathrm{AB}$ \\
\cline { 3 - 7 } & Kappa caseina & 0.60 & 0.40 & 0.30 & 0.10 & 0.60 \\
& Beta lactoglobulina & 0.15 & 0.85 & 0.10 & 0.80 & 0.10 \\
\hline
\end{tabular}

A: Alelo A; B: Alelo B; AA: Homocigoto A; BB: Homocigoto B; y $\mathrm{AB}$ : Heterocigoto AB.

Estudios realizados por Lunder et al. (1997) indican que la asociación entre las variantes Caseína (CSN), la producción y composición de la leche ha sido de gran importancia en la raza europeas, determinando que la variante B de Kappa caseína ha sido reconocida como superior para la calidad en razas lecheras europeas.

Cervantes et al. (2007) reportan que el alelo A de Kappa caseína en cinco de seis poblaciones analizadas presentaron frecuencias alélicas de 0.700 para la razas Holstein x Cebú, 0.300 para Holstein, 0.702 en Pardo Suizo, 0.298 en Pardo Suizo x Cebú, 0.511 para Cebú y 0.489 en Criollo lechero tropical; en cambio el alelo B presentó frecuencias alélicas igual a 0.429 para Holstein x Cebú, 0.571 en Holstein, 0.740 para Pardo Suizo, 0.260 en Pardo Suizo x Cebú, 0.571 en Cebú y de 0.429 en Criollo lechero tropical. Obteniendo mayor frecuencia el alelo B del gen de Kappa caseína en el cruce Pardo Suizo y Cebú seguido del Pardo Suizo, por la alta presencia de este alelo hace particularmente adecuada a dichas razas para procesos industriales lácteos con composición proteica y grasa aceptables.

Los resultados de este estudio son similares a los obtenidos por Almeyda et al. (2016), quienes registraron mayor frecuencia del genotipo AB del gen Kappa caseína en el ganado criollo de Perú con 0.56 en 27 animales de 48 analizados, y una frecuencia alélica para A y B de 0.552 y 0.448 respectivamente.

En este estudio los resultados son diferentes a los de Dogru y Ozdemir (2009), quienes reportan frecuencias genotípicas de Kappa caseína de $0.1935,0.2043$ y 0.6022 para los genotipos $\mathrm{AA}, \mathrm{BB}$ y $\mathrm{AB}$, respectivamente. En tanto las 
frecuencias alélicas fueron de 0.495 y 0.505 para los alelos A y B, respectivamente, en raza Pardo Suizo, indicando mayor número de genotipos $\mathrm{AB}$ y $\mathrm{BB}$, mientras tanto la frecuencia de alelos predominante en el $\mathrm{B}$.

Van Eenennaam y Medrano (1991) demostraron que la leche de los animales con genotipo CASא $\mathrm{AB}$ contiene una mayor proporción de $\kappa-\mathrm{CN} \mathrm{B}$. Esto sugiere que dicho alelo tiene un mayor nivel de expresión con respecto a la variante A en la glándula mamaria de los bovinos.

Los resultados en este estudio para $\beta$ eta Lactoglobulina son similares a los obtenidos por Morillo et al. (2014) obteniendo frecuencias alélicas en razas criollo limonero y Carora de Venezuela con alelos A y B, para criollo limonero $0.21,0.79$ y para Carora 0.34, 0.66, respectivamente, presentando mayor frecuencia el alelo $\mathrm{B}$ en poblaciones bovinas Bos Taurus Bos indicus, como Cebuinas brasileñas y en razas Nórdicas. Rojas et al. (2010) determinaron frecuencias genotípicas del gen de Beta Lactoglobulina de 0.07, 0.29, 0.64 para los genotipos AA, $\mathrm{AB}, \mathrm{BB}$ respectivamente, y en las frecuencias alélicas 0.22 para el alelo AA y de 0.78 para el alelo $\mathrm{B}$, predominando la variante $B$.

\section{CONCLUSIONES}

Mediante la técnica PCR convencional y PCR-FRLP se determinó que el genotipo predominante en hembras bovinas para el gen de Kappa caseína fue el heterocigoto AB con 0.60 (12/20), mientras que en ßeta Lactoglobulina fue el genotipo homocigoto BB con 0.80 (17/20), siendo los genotipos BB de Kappa caseína y ßeta Lactoglobulina los de mayor rendimiento quesero en la industria láctea.

El resultado para el gen de Kappa caseína demostró que el alelo predominante fue el A con 0.60 sobre el alelo B con 0.40 , estos resultados sugieren hacer mejoras genéticas para obtener resultados favorables en la producción y rendimiento quesero.

Para el gen de la ßeta Lactoglobulina los resultados fueron de 0.85 para el alelo B y 0.15 para el alelo A, predominando el alelo $\mathrm{B}$ sobre el alelo $\mathrm{A}$, el predominio de estos alelos está determinado por las razas y el encaste existente en el hato ganadero nicaragüense.

\section{REFERENCIAS BIBLIOGRÁFICAS}

Almeyda, M. R., Rosadio A., R. y Maturrano H. L. (2016). Genotipos del gen de Kappa Caseína en Ganado Bovino Criollo del distrito de Bambamarca, Cajamarca, Perú. Revista de Investigación Veterinaria del Perú, 27 (1), 82-90. https://doi.org/10.15381/rivep. v27i1.11452

Benavides Castro, T. A. (2003). Efecto de las variantes genéticas A y B de $\kappa$-Caseína y $\beta$-lactoglobulina sobre las propiedades de coagulación de la leche [Tesis de grado, Universidad Austral de Chile]. Tesis Electrónicas UACh. http://cybertesis.uach.cl/tesis/ uach/2003/fab456e/sources/fab456e.pdf

Cervantes, P., Luna, M., Hernández, A., Pérez-Gil, F., Ponce, P. y Uffo, O. (2007). Polimorfismo Genético en el locus de la Kappa Caseína, en vacas de diferentes razas y cruces en el trópico mexicano. Revista Salud Animal, 29(2), 78-84. http://scielo.sld.cu/pdf/rsa/v29n2/ rsa02207.pdf

Dogru, U. y Ozdemir, M. (2009). Genotyping of kappa-casein locus by PCR-FRLP in Brown Swiss cattle breed. Journal of animal and veterinary advances, 8(4), 779-781. http://docsdrive.com/pdfs/medwelljournals/javaa/2009/779-781.pdf

Doyle, J. J. y Doyle, J. L. (1990). Isolation of plant DNA from fresh tissue. Focus, (12), 13-15.

Espinoza Baltodano, J. A. y Urbina Contreras, E. B. (2016). Buenas Prácticas pecuarias del ganado bovino en Nicaragua. incidencia de las buenas prácticas pecuarias en la producción de leche en el municipio de Santo Tomas, departamento de Chontales (2013-2015) [Tesis de grado, Universidad Nacional Autónoma de Nicaragua]. Repositorio Institucional UNAN-Managua. https://repositorio.unan. edu.ni/2826/7/17005.pdf

Falconer, D. S. y Mackay, T. F. C. (2001). Introducción a la genética cuántica. Editorial ACRIBIA.

Giménez Ramírez, J. C. (2016). Raza bovina pardo suizo. Pregón Agropecuario. http://www.pregonagropecuario.com/cat.php?txt=8015

Griffiths, A. J. F., Miller, J. H., Suzuki, D. T., Lewontin, R. C. y Gelbart, W. M. (2002). Genética. McGraw-Hill Interamericana.

Hernández-Rodríguez, A. y Trejo-Mendinilla, F. (2014). Estudio Genético Poblacional de Frecuencias Alélicas para 15 marcadores STR presentes en la población del Estado de Zacatecas aplicado a la práctica forense. Archivos de Medicina, 10(1), 1-24p. https://www. archivosdemedicina.com/medicina-de-familia/estudio-gentico-poblacional-de-frecuencias-allicas-para-15-marcadores-str-presentesen-la-poblacin-del-estado-de-zacatecas-aplicado-a-la-prctica-forense.pdf

Instituto Nicaragüense de Estudios Territoriales. (2018). Dirección general de meteorología anual: Resumen meteorológico anual. https:// www.ineter.gob.ni/met.html

López, O. (2019). Como se encuentra el sector lácteo de Nicaragua. CANISLAC. https://canislac.com/como-se-encuentra-el-sectorlacteo-de-nicaragua/

Lunder, A., Nilsson, M. y Janson, L. (1997). Marked effect of beta lactoglobulin polimorphism on the ratio of casein to total protein in milk. Jounal of Dairy Science, 80(11), 2996- 3005. https://doi.org/10.3168/jds.S0022-0302(97)76266-0 
Morillo, M., Acosta, A. y Uffo, O. (2014). Determinación de las frecuencias alélicas de tres lactoproteínas en bovinos Criollo Limonero y Carora de Venezuela. Revista de Salud Animal, 36(3), 178-188. http://revistas.censa.edu.cu/index.php/RSA/article/view/502/455

Organización de las Naciones Unidas para la Alimentación y la Agricultura. (2014). El papel de la FAO en la producción animal. http:// www.fao.org/animal-production/es/

Requena, F. D., Agüera, E. I. y Requena, F. (2007). Genética de la caseína de la leche en el bovino Frisón. Revista Electrónica de Veterinaria, 8(1), 1-9. https://www.redalyc.org/pdf/636/63613304013.pdf

Rojas, I., Aranguren-Méndez, J., Portillo, M., Villasmil-Ontiveros, Y., Valbuena, E., Rincón, X., Contreras, G. y Yañez, L. (2009). Polimorfismo genético de la kappa-caseína en ganado criollo limonero. Revista Científica, 19(6), 645-649. http://ve.scielo.org/scielo. php?script=sci_arttext\&pid=S0798-22592009000600012

Rojas, I., Aranguren-Méndez, J., Portillo, M., Villasmil-Ontiveros, Y., Rincón, X. y Contreras, G. (2010). Frecuencias Alélicas de Beta-Lactoglobulina en Ganado Criollo Limonero. Revista Cientifica, 20(2), 176-180. http://ve.scielo.org/scielo.php?script=sci_ arttext\&pid=S0798-22592010000200009

Ruiz, E. A. (2011). Evaluación genético molecular de pie de cría suizo americano en el Estado de Chiapas [Tesis de doctorado, Instituto de Enseñanza e Investigación en Ciencias Agrícolas]. Academia. https://www.academia.edu/3107193/Evaluaci\%C3\%B3n_ gen $\% \mathrm{C} 3 \% \mathrm{~A} 9$ tico-molecular de pie de cr\%C3\%ADa suizo americano en el estado de Chiapas

Uffo, O., Burriel, M. I., Martínez, S., Ronda, R., Osta, R., Rodellar, C., y Zaragoza, P. (2006). Caracterización genética de seis proteínas lácteas en tres razas bovinas cubanas. Animal Genetic Resources Information, (39), 15-24.

Van Eenennaam, A. y Medrano, J. F. (1991). Milk Protein Polymorphisms in California Dairy Cattle. Journal of Dairy Science, 74(5), 17301742. https://doi.org/10.3168/jds.S0022-0302(91)78336-7

Zambrano Varón, J. L. y Díaz, S. (2012). Guía para la correcta toma de sangre en bovinos a partir de la vena coccígea y de la vena yugular externa. http://medicinaveterinariaydezootecnia.bogota.unal.edu.co/fileadmin/FVMZ/Servicios/bioetica/Pro_autorizados/001_Guia_ toma_sangre_bovinos.pdf 